\title{
On E-commerce Integrity Security and Technical Support
}

\author{
Dong Yanqiu \\ Engineering Training Center \\ Shenyang Aerospace University \\ Shenyang, China
}

\author{
Liu Xueping \\ Engineering Training Center \\ Shenyang Aerospace University \\ Shenyang, China
}

\begin{abstract}
With rapid popularization of Internet, Ecommerce is not only a development direction of future trade, but also a requirement of China to implement independent innovation and actively take part in international competition as a brand new mode of trade and business model. In recent years, e-commerce develops rapidly in China, but China currently has many restriction factors in the e-commerce field. Integrity issues, in particular, have seriously restricted sound development of e-commerce and become a major bottleneck to China's E-commerce development.
\end{abstract}

Keywords-E-commerce; Integrity security; Third party payment; Integrity consciousness

\section{BACKGROUND OF E-COMMERCE INTEGRITY SECURITY AND TECHNICAL SUPPORT}

With increasingly popularization of personal computer and continuous maturity of network technique, Internet is walking into tens of thousands of households and becomes an indispensable part of people's daily life. In 21 st century, the mankind gets foot in the door of information society. The wave of Internet economy brings huge impact to the entire economic society, and simultaneously, the new economic model "e-commerce" becomes a great and new topic for circles of economics and management study as well.

As a new commercial model in 21 st century, ecommerce has unlimited development prospect, and its operation modes mainly include $\mathrm{B}$ to $\mathrm{B}, \mathrm{B}$ to $\mathrm{C}, \mathrm{B}$ to $\mathrm{G}, \mathrm{C}$ to $\mathrm{G}$ and $\mathrm{C}$ to $\mathrm{C}$, in which $\mathrm{C}$ to $\mathrm{C}$ refers to consumer-toconsumer e-commerce. In this commercial mode, consumers conduct mutual personal trading through the Internet in such way as auction. This mode has provided consumers with convenience and material benefit and is to create value through price induced by value between consumers and intermediary services of suppliers on $\mathrm{C}$ to $\mathrm{C}$ trading platform. However, since the fact that in addition to virtuality and time transcending, $\mathrm{C}$ to $\mathrm{C}$ e-commerce is characterized by: individual is the major participant, low entering barrier and participants can be anonymous and easy to register, which have determined its uncertainty, high dynamics, virtuality of trading individual and finiteness in e-commerce technology and stage of management development. All these cause great transaction exposure, repeated occurrence of online fraud phenomena, and those who want to be engaged in $\mathrm{C}$ to $\mathrm{C}$ e-commerce flinch, which have greatly impeded development of e-commerce. Hence, reducing transaction exposure of $\mathrm{C}$ to $\mathrm{C}$ e-commerce and promoting integrity transaction have become important questions for study of safety problem of online transaction. This paper aims to apply the economics of e-commerce, network economics and the economics of contracts theories to analyze transaction safety and integrity management in China's C2C e-commerce and attempts to seek for an effective integrity management mechanism and then carries out tests of it. It also studies on theoretical significance of integrity mechanism of China's C2C e-commerce and practical significance of integrity issue on China's C2C e-commerce.

\section{CONSTRUCTION STRATEGY OF NETWORK AND SOCIAL ENVIRONMENT OF INTEGRITY SECURITY}

\section{A. Strategy of network environment construction}

The third party payment and hard credit better avoid occurrence of dishonest behaviors like "making collection without delivering goods" and "delivering goods without making collection", pay a role in integrity guarantee and make sure that the transaction goes well. Nevertheless, how to avoid product quality problem and lower occurrence rate of online fraud? Large-scale e-commerce platform currently adopts credit rating and offence reporting system and the method of mutual evaluation between buyers and sellers on platform to reflect credit rating by praise degree. Evaluative feedback mechanism after transaction encourages honest and credible participants to accumulate good creditworthiness, to stay in the market in the long term and to knock out dishonest ones, thus reducing occurrence of dishonest behaviors. At present, Taobao, eBay and Paipai adopt the manner of credit rating to strengthen website integrity security. The manner of credit rating and management method are basically the same. Specific measures are as follows:

After transaction, both parties make evaluation on the deal, and evaluation is divided into three classes, "Positive", "Moderate" and "Negative". Numbers of all kinds of evaluations will be accumulated, and evaluation on participants is available for inquiry.

Different credit ratings of different participants can be obtained and corresponding transaction limits to different credit ratings made through mathematical model based on feedback evaluation. Current website credit rating method can be understood according to credit rating rules of Paipai.

1) Establish perfect credit rating system

\section{a) Credit rating method}

Having mutual evaluation after the deal is closed, and credit rating includes three parts: positive $=+$, moderate $=0$ and negative $=-$. Buying credit rating and selling credit 
rating are fully separated, which can effectively reduce the behavior of vicious speculation of credit. Later, it can be considered that sellers are allowed to control buyers' bid through setting parameter of "Buyers' Level Restriction" so as to reduce occurrence of vicious auction.

\section{b) Calculation of credit}

Credit of Paipai is associated with two factors: one is transaction times and the other is transaction amount. Calculation formula of credit: credit=credit rating* weight of transaction amount.

\section{c) Restriction rule of credit point}

For non-TenPay transaction, buying evaluation from the same user in one natural month only accumulates 1 point, and selling evaluation only accumulates 1 point. No point is accumulated to evaluation when this restriction is exceeded.

For TenPay transaction, buying evaluation from the same user in one natural month can accumulate 10 points at most, and selling evaluation can accumulate 10 points at most. No point is accumulated to evaluation when this restriction is exceeded.

If several TenPay transactions occurred to same commodity between same buyer and same seller, transaction evaluation on the first deal after mutual evaluation takes effect and accumulates points, while other TenPay transactions don' $t$. The restriction only takes effect within 7 days (including seventh day) after the latest deal of the commodity between same buyer and same seller is closed. For instance, one TenPay transaction of same commodity between same buyer and same buyer has already been accumulated on October 1, and the second deal on October 9 can also be accumulated when the mutual evaluation is accomplished.

\section{d) Other indexes}

Positive rate $=$ total number of positive/total number of evaluation

Evaluation rate $=$ total number of evaluation/total number of successful transaction

\section{e) Restricted transaction rules}

When selling credit is under -4 , he is not allowed to continue releasing commodity after logging in. After the commodity is compiled, information of this commodity after modification is only preserved in warehouse. Other moves have no restriction.

When buying credit is under -2 , he is not allowed to continue buying commodity after logging in. Other moves have no restriction in addition to buying commodity.

The unpaid transactions of buyer under processing must not be over 20 at most.

The unpaid transactions of buyer under processing must not be over +5 of his buying credit. Note: the unpaid transaction under processing= unfinished transaction not paid by TenPay+ leading bidding transaction. This rule is applied to avoid user' $\mathrm{s}$ vicious auction and causing damage to seller.

\section{2) Perfect reporting system}

Large-scale e-commerce website generally offers reporting system, a measure aiming at illegal behaviors generated by online transaction adopted by e-commerce platform to protect user's legitimate interest and create honest transaction environment. Report is the supervision before the event of users' behavior of violating network transaction rules occurred, and it is beneficial to establish honest environment of network transaction. The whole reporting system is composed of report, punishment and appeal. Reporting contents include selling ban goods, illegal release of commodities, commodity infringement, credit speculation, bull campaign and buying prohibited goods, etc. The reported party can make an appeal. Once the report is verified, the reported party shall be punished accordingly.

Reporting system aims to create just, open, fair and harmonious environment of e-commerce integrity security. Through setting up reporting system, occurrence of relevant dishonest behaviors can be effectively reduced.

\section{3) Establish uniform regulator}

Admittedly, various e-commerce platforms have taken many measures to construction of integrity security. Credit rating conducts level-to-level administration on both seller and buyer, reporting system punishes dishonest behavior, and some websites also push out the move of "compensation in advance". All these have made certain contribution to their integrity security construction Nevertheless, no e-commerce platform is equipped with an effective and perfect restriction mechanism, making the network filled with many forged and fake commodities and merchants. Each e-commerce platform is fragmented, and there is no uniform standard for information evaluation and reporting system. Evaluation method of credit rating, calculation method of credit, management method and reporting and punishment measures of various platforms are different. Each e-commerce platform is fragmented, thus the integrity information cannot be shared. Therefore, a uniform credit rating and regulator is required to be established. Credit rating and regulator should implement following functions:

Establish and perfect uniform credit rating mechanism. Adopt uniform credit rating manner, credit calculation method and credit management method to make credit rating on both e-commerce trading parties and conduct graduation management of enterprise and individual credit. Offer website calling interface. Credit rating of every ecommerce website adopts uniform credit rating mechanism.

Establish credit information database. Collect credit information from enterprise and individual registration, operation, credit rating, reporting and rewards and punishment, etc. Input these data into credit information database timely and correctly to implement sharing of enterprise and individual credit information.

Provide inquiry and publicity service of enterprise and individual credit information for the public. The public is able to inquire credit status of related enterprises and individuals from query system conveniently. Credit rating and regulator should publicize enterprises and individuals with good credit as well as misconduct of dishonest enterprises and individuals through the Internet and other media at both regular and irregular periods to arouse extensive supervision of the society.

Currently, credit information related to some enterprises and individuals is closed in China. It is impossible to inquire others' credit information in market entity. All departments treat this kind of information as business secret or individual privacy and take measures to protect it, making e-commerce traders conduct many commercial activities under circumstance of not knowing 
credit of the opposite, which has increased risk of ecommerce greatly.

\section{B. Construction strategy of social environment}

\section{1) Existing problems in social environment}

Although China has already formulated some laws and regulations related to e-commerce, which has greatly propelled construction of e-commerce integrity security, China's e-commerce integrity environment is not optimistic. At present, laws and regulations related to ecommerce integrity security are imperfect and lacking of punishment mechanism towards dishonest behavior, which partly indulges occurrence of dishonest behavior.

Hence, perfect laws and regulations have to be established and integrity legislation accelerated to form strong constraining force over integrity system and create good laws and regulations environment of integrity. Therefore, construction of e-commerce integrity security must combine laws and regulations of integrity with morality of integrity, conduct a nation-wide integrity and moral education and inherit, transform and develop integrity idea in traditional morality, making it combine with requirement of e-commerce, thus forming integrity and morality standard and building e-commerce environment of "honor being honest and shame being dishonest". As a consequence, e-commerce participants follow integrity and moral rule consciously. Through integrity and moral education, people's concept and consciousness of integrity are cultivated and integrity and morality are deeply accepted by people, thus boosting China's e-commerce to move towards good direction.

\section{2) Related measures to solve existing problems}

a) Perfection and restriction of laws and regulations

China currently is quickening the construction of ecommerce laws and regulations by establishing perfect laws and regulations and increasing punishment intensity on dishonest behavior. The State Council issued Opinions on Accelerating Development of E-commerce on January 8, 2005. China issued and implemented Law of Electronic Signature on April 1, 2005. On March 11, 2006, Creditappraisal Centre of China's E-commerce Association issued Fundamental Norms of E-commerce Integrity of Chinese Enterprises. The first policy document to specially guide development of e-commerce in China was Opinions on Accelerating Development of E-commerce, issued by the State Council. It has interpreted the country's several important opinions on China's development of ecommerce, defined guiding ideology and principle of China's development of e-commerce and established China's six moves in promoting development of ecommerce.

\section{b) Construction of ideological and moral education}

Social environment construction of integrity security has to focus on laws and regulations construction, but laws are not omnipotent and have their own limitation. Moral education is able to make up deficiency of laws and regulations. In particular, moral education in traditional culture is a self-disciplinary constraint on fluke mind and an intangible power, so it often plays the role that rule by law can't. Integrity and honesty education should be continuously conducted in the whole society for integrity is the foundation of all morality. Being honest is a golden rule of market economy. Integrity and honesty are of common value to anyone, any nationality and any nation.

\section{CONCLUSION}

In recent years, e-commerce develops rapidly in China and e-commerce transactions are growing, thus integrity security problems become more prominent and become a common concern to netizens. China's government pays high attention to how to improve integrity security of ecommerce. The General Office of the State Council issued Opinions on Accelerating Development of E-commerce and proposed guiding opinions on construction of integrity security; later, it has introduced Law of the People's Republic of China on Electronic Signature, which has established legal status of electronic signature and laid foundation for integrity transaction. Enterprise ecommerce entities also attach great importance. Ecommerce Credit Union has been established at the end of 2004 and Fundamental Norms of E-commerce Integrity of Chinese Enterprises introduced at the beginning of 2006 through preparation in 2005 , which have played a powerful role in promoting construction of integrity security. Furthermore, e-commerce websites also adopt specific measures to increase integrity security of e-commerce transaction, e.g. third party payment to offer integrity guarantee and buying and selling credit rating.

In a word, establishment of e-commerce integrity security environment is a system engineering that requires mutual efforts of the government, e-commerce enterprises (websites) and e-commerce trading entities in technical support and environmental construction, etc. and establishing integrity security system of e-commerce.

\section{REFERENCES}

[1] Tan Chunhui online consumer personal integrity problem research in China [D]. Central China normal university., 2012

[2] CZC Shen Nali. Our country electronic commerce integrity management mechanism research (D) .chongqing university, 2013

[3] China's e-commerce integrity problems and countermeasures research (D) . Suzhou university, 2014

[4] Deng Xiao Yi, Shen Nali. Analysis of C2C Transaction Exposure and Integrity Management Mechanism, Special Zone Economy, 2011(4).

[5] Ma Guiqin. Establishment of Integrity Environment Guarantees Secure and Healthy Development of China's E-commerce [J] Development, 2012(7).

[6] Sun Chao. Third Party Payment is the Booster to E-commerce [J] Journal of Hubei Polytechnic Institute, 2013(3).

[7] He Guihe. Discussion and Analysis of Individual Integrity Crisis of Online Consumers [J]. Technology Review, 2011(1).

[8] Yong Zhili. Technology of Digital Certificate [J]. China Modern Technical Equipment, 2010(1).

[9] Wang Xiang. Important Mechanism to Guarantee E-commerce Security-Electronic Identity Authentication [J]. Modern Economic Information, 2011(7).

[10] Zhu Dan, Cai Na. Study on E-commerce Integrity [J]. Lanzhou Academic Journal, 2010(6).

[11] Chen Lixing. Discussion on Mode of Third Party Payment [J], Market Modernization, 2012(085).

[12] Li Erliang, Zhu Qiwei. Cash in Transit Issue in Third Party Payment Platform [J]. Social Scientist, 2014(3).

[13] He Zhong, Li Meicun. Analysis Based on Security Issue of Electronic Payment [J]. Fujian Computer, 2012(02).

[14] Guan Jian. Discussion on Protecting Legal Rights of Online Shopping Consumers [J]. Modern Economic Information, 2013(7). 
[15] Shi Da, E-commerce: Calm Thinking in Enjoyment [J]. Western Forum, 2012(09).

[16] Qi Shi. Reflection on Integrity [J]. Qianjin Forum, 2014(9).

[17] Chen Yongqiang. Integrity-Bottleneck of China's E-commerce [J]. Journal of Hangzhou Teachers College (Natural Science),2012(2).

[18] Lv Xuedian. On the Incident of "\$ 116 for a Passert"--Honesty Crisis of E-commerce [J]. Journal of Shijiazhuang University of Economics, 2013(02).

[19] Jin Zhen, Zhang Jilan. Study on E-commerce Credit System [J]. Journal of Information, 2014(12).

[20] Jin Zhen. E-commerce and Integrity [J]. Information Science, 2013(10).

[21] Zhang Bo. Anlaysis of Lacking of Honesty in E-commerce [J]. Pioneering with Science \& Technology Monthly, 2012(05).

[22] Fang Zhen. Development of E-commerce Must Establish Perfect Integrity Mechanism [J]. Journal of Liaoning Economic Vocational Technological Institute, 2014(01).

[23] Zhang Jilan. Current Status Analysis of China's E-commerce Credit System [J]. Modern Information, 2014.

[24] Jiang Lingmin. Study on Current Status and Countermeasure of China's E-commerce Development [J]. Business Studies, 2013.

[25] Zheng Jianyou. Current Situation and Regulatory Advice of Third Party Online Payment Market [J]. Financial Accounting. 2012(07).

[26] Zhang Kuanhai, Zhang Jing. Analysis and Research of Third Party Payment [J]. China Credit Card, 2013(14).

[27] Yang Guoming, Li Baohua. Discussion on Legal Issue of Third Party Payment [J]. Financial Economy, 2013(08).

[28] Liao Minhui, Restraining Factor and Countermeasure Suggestion on Development of Third Party Payment Platform in China [J]. Market Modernization, 2011(22).

[29] Establishment of Credit System [J].Pioneering, 2012(05).

[30] Huang Xiao. Analysis of Construction of China's E-commerce Credit System [J]. Journal of Beijing Electronic Science and Technology Institute, 2012(09).

[31] Zhang Cheng. Shackles in Development of China's E-commerce [J]. Contemporary Manager (late ten-day periodical), 2012(03). 